(2)

\title{
Lifestyle diseases and cardiovascular risk factors are interrelated to deficiencies of major substrates in ATP synthesis
}

This article was published in the following Dove Press journal:

Vascular Health and Risk Management

16 September 2010

Number of times this article has been viewed

Jørn Ditzel

Hans-Henrik Lervang

Department of Endocrinology, Center for Prevention of Struma and Metabolic Diseases, Aalborg University Hospital, Aarhus University,

Aalborg, Denmark
Correspondence: Hans-Henrik Lervang Department of Endocrinology, Aalborg University Hospital, Aarhus University, 9000 Aalborg, Denmark

Tel +45 99326। 25

Fax +4599326008

Email hhl@rn.dk; jditzel@ofir.dk
Abstract: Recent studies on diabetes and metabolic syndrome indicate a common disturbance of inorganic phosphate $(\mathrm{Pi})$ metabolism. $\mathrm{Pi}$ is an important substrate in the formation of adenosine triphosphate (ATP), and many lifestyle diseases and cardiovascular risk factors similarly show deficiencies in either 1 or 2 major components of ATP synthesis. Age, male gender, hypertension, obesity, hypertriglyceridemia, metabolic syndrome, and diabetes mellitus are all associated with hypophosphatemia. In addition, tobacco smoking, hyperchylomicronemia, hypertension, and diabetes may involve defects in tissue oxygen delivery. Hypophosphatemia may lead to a critical decrease in intracellular Pi and to mitochondrial dysfunction, which might be counteracted by the pharmacological use of fructose 1,6-diphosphate.

Keywords: hypophosphatemia, hypoxia, diabetes, metabolic syndrome, hypertension

\section{Introduction}

Inorganic phosphate $(\mathrm{Pi})$ is the ubiquitous anion required for intermediate metabolism and energy-transfer mechanisms. Pi is a vital component of DNA and RNA, and it is also present in phospholipids in membranes. Pi participates in both glycolysis and oxidative phosphorylation, the 2 major sources of adenosine triphosphate (ATP). In glycolysis, Pi is a substrate for glyceraldehyde-3-phosphate dehydrogenase and stimulates the activity of hexokinase and phosphofructokinase. In oxidative phosphorylation, $\mathrm{Pi}$ is a putative signaling molecule and takes part in the phosphorylation potential ATP/ADP $\times$ Pi. Bose et $\mathrm{al}^{1}$ have demonstrated in a multiparameter monitoring system applied to heart and skeletal muscle mitochondria that Pi controls the oxidative metabolism in a balanced fashion. Optimal amounts of both Pi and oxygen are required for a continuous supply of free energy according to the classical equation for oxidative metabolism: ${ }^{2} 3 \mathrm{ADP}+3 \mathrm{Pi}+1 / 2 \mathrm{O}_{2}+\mathrm{NADH} \rightarrow 3 \mathrm{ATP}+\mathrm{NAD}^{+}+\mathrm{H}_{2} \mathrm{O}$. If the production of ATP is interrupted or stopped for any reason, it may have serious consequences and may possibly lead to cell injury or cell death.

Plasma Pi is held within narrow limits through a complex interplay between intestinal absorption, exchange with intracellular and bone storage pools, and renal reabsorption. Intestinal absorption is mediated by sodium-phosphate cotransporter protein $\mathrm{NaPi}-\mathrm{IIb}$, which can be up-regulated and down-regulated when needed to maintain and exchange with intracellular and bone storage pools and renal reabsorption. The kidneys are the major regulators of Pi homeostasis, controlled by both hormonal and nonhormonal factors, and can increase and decrease Pi reabsorption capacity to accommodate the Pi need. The critical regulated step in this process is the transport of 
Pi across the luminal membrane of the renal proximal tubules by the sodium phosphate-dependent cotransporter proteins that are bound to the brush border membrane, and the last intracellular loop of NaPi-IIa contains sequence information that confers parathyroid hormone (PTH) sensitivity. ${ }^{3}$ Because of the extensive literature, it is beyond the scope of this article to go further into details in the regulation of Pi homeostasis by PTH, vitamin D, phosphocalcins as fibroblast growth factor 23, phosphate regulating and Klotho genes, and more, but readers are referred to excellent reviews. ${ }^{4,5}$

Recently, we demonstrated a paradoxical metabolic imbalance in Pi from the early onset of diabetes, which may lead to a reduction in high energy phosphates and tissue hypoxia. ${ }^{6,7}$ This imbalance may be associated with the risk of late diabetic complications including cardiovascular disease. Hypophosphatemia, likewise, has been reported in studies of large numbers of individuals with metabolic syndrome..$^{8,9}$ As metabolic syndrome also has been shown to be closely associated with cardiovascular diseases, ${ }^{10,11}$ we were stimulated to examine through Medline (PubMed), Embase, and reference lists whether other lifestyle diseases and risk factors may show similar biochemical alterations.

In this article, we will present evidence suggesting that many lifestyle diseases and risk factors are interrelated to deficiencies in 1 or 2 major components for optimal generation of ATP, eg, phosphate and/or oxygen.

\section{Increasing age and male gender}

More than $80 \%$ of deaths from coronary heart disease occur in patients of 65 years or older, an age at which female heart attack patients are more likely to die than men despite the fact that men have a greater risk of heart attack and suffer heart attacks earlier in life. Even after menopause, when women's death rate from heart disease increases, it is not as great as men. ${ }^{12}$

The concentration of plasma $\mathrm{Pi}$ and the maximal renal tubular reabsorption of phosphate $\left(T_{\mathrm{mPO} 4} / \mathrm{GFR}\right)$ are closely related to age and sex, with the highest values occurring in childhood. In adults, plasma Pi in men declines with age almost linearly, whereas in women under the age of 45 , the values overlap those of men and then increase between 45 and 54 years before declining thereafter. The practical implication is that phosphate-depleting disorders, such as diabetes and metabolic syndrome, might induce hypophosphatemia more easily in older persons because of the diminished tubular capacity for phosphate reabsorption before the development of such disorders. ${ }^{13}$

\section{Diabetes mellitus}

Cardiovascular diseases are the leading cause of diabetesrelated deaths. Substantial clinical and experimental evidence suggest that both diabetes and insulin resistance cause endothelial dysfunction, which may diminish the antiatherogenic role of the vascular endothelium. In this respect, it is of interest that hypophosphatemia has been shown to increase insulin resistance and induce glucose intolerance. ${ }^{14-17}$ Hypophosphatemia is a common finding in both type 1 and type 2 diabetes, and several investigators have found decreased concentration of $\mathrm{Pi}$ in poorly regulated diabetic patients and slightly elevated levels when optimally controlled. ${ }^{6}$

Oxyhemoglobin dissociation is a measure of the ability of the red cells to release oxygen as they pass through the microcirculation. The position of the oxyhemoglobin dissociation curve (ODC) is often expressed by the $\mathrm{P}_{50}$, (oxygen tension at $50 \%$ oxygen saturation). The position of the ODC is dependent of red cell 2, 3-diphosphoglycerate (2, 3-DPG) concentration. Oxygen release to tissues can be increased by interaction with a number of organic phosphates, primarily 2 , 3 -DPG. In a variety of situations where tissue oxygenation is impaired, the 2, 3-DPG level rises, producing a proportional increase in $\mathrm{P}_{50}$ (a right shift of ODC). Such changes have been reported in anemia, ${ }^{18,19}$ cardiac failure, ${ }^{20,21}$ and cardiopulmonary insufficiency. ${ }^{22,23}$ Conversely, impaired synthesis of 2, 3-DPG is associated with a left shift of the ODC leading to a decreased delivery of oxygen to the venous end of the microvasculature (venous part of capillaries and venules).

In newly diagnosed, nonacidotic, type 1 diabetic patient's plasma, the Pi concentration was normal at admission, lower on the day after initial insulin administration, and slightly above normal on the day when the best metabolic control is achieved. Red cell 2, 3-DPG exhibited the same fluctuating pattern, and Pi correlated closely with 2, 3-DPG ( $r=0.61$, $P<0.001)$. Red cell 2, 3-DPG correlated equally well with $\mathrm{P}_{50}$ of the ODC. ${ }^{24,25}$

To clarify the underlying mechanism leading to hypophosphatemia, a study was performed in comparable groups of ambulatory, nonacidotic, insulin-dependent diabetic and healthy children. The average plasma Pi was significantly lower in the 26 children with diabetes compared with 28 healthy children ( 1.36 vs $1.48 \mathrm{mmol} / \mathrm{L}, P<0.005)$. In children with diabetes, the urinary phosphate excretion rate was significantly elevated ( $1.19 \mathrm{vs} 0.43 \mathrm{mmol} / \mathrm{h}, P<0.001)$, and phosphate excretion rate positively correlated with the urinary excretion rate of glucose $(r=0.53, P<0.01)$ and with the blood glucose $(r=0.52, P<0.01)$. The renal 
threshold concentration of phosphate $\left(T_{\mathrm{mPO} 4} / \mathrm{GFR}\right)$ was significantly suppressed in the children with diabetes $(1.23$ vs $1.73 \mathrm{mmol} / \mathrm{L}, P<0.001)$. This disturbance was related neither to changes in serum PTH nor to changes in growth hormone, but inversely correlated with the degree of hyperglycemia $(r=0.61, P<0.001)$. The study demonstrates an abnormality in tubular phosphate reabsorption, which is related to glycemic regulation. ${ }^{26}$

However, in ambulatory subjects with juvenile diabetes with no evidence of vascular complications, despite an almost $30 \%$ increase in the concentration of $2,3-\mathrm{DPG}$ at the same hemoglobin content, the $\mathrm{P}_{50}$ of the ODC was not increased. ${ }^{27}$ This may be explained by the fact that hemoglobin $\mathrm{A}_{1 \mathrm{c}}$ has increased the oxygen affinity and may react less readily with 2, 3-DPG compared with regular hemoglobin A. ${ }^{28}$

Therefore, in patients with both type 1 and type 2 diabetes, there is a close correlation between the Pi concentration in plasma and improved diabetes control. In order for patients with diabetes to achieve optimal oxygen delivery to tissues, the concentration of 2, 3-DPG and Pi must be higher than in healthy persons, partly because the red blood cells of patients with diabetes contain higher concentrations of hemoglobin $\mathrm{A}_{1 \mathrm{c}}$.

\section{Obesity}

Obesity is a major risk factor for cardiovascular diseases. Lindgärde and Trell ${ }^{29}$ found an inverse correlation between plasma Pi and body weight in 752 men born in 1926. Other parameters of minerals with possible relevance to their findings were not found. In 194 subjects with a wide range of body mass index (BMI), Lind et $\mathrm{al}^{30}$ found that plasma Pi inversely correlated with BMI and fat distribution. PTH was not significantly correlated with any obesity parameters. Håglin et $\mathrm{al}^{8}$ conducted a large study of 1,272 women in whom serum phosphate inversely correlated with BMI.

\section{Dyslipidemia}

In apparently healthy persons, total cholesterol and lowdensity lipoprotein cholesterol positively correlated with increasing Pi levels, and triglyceride concentration negatively correlated with plasma Pi levels. ${ }^{9}$

Hypertriglyceridemia and especially hyperchylomicronemia have been found to interfere with tissue oxygen delivery. A marked left shift of the ODC has been demonstrated in familial type 1 hyperlipoproteinemia (familial combined hyperlipidemia), in diabetic and nondiabetic persons with hyperlipoproteinemia type V (mixed hypertriglyceridemia), and in blood mixed with lipid emulsions. ${ }^{31-33}$ The reason for this negative effect on tissue oxygen delivery might be an abolishment of the $\mathrm{pH}$ difference across the erythrocyte membrane resulting in a displacement of the ODC to the left by the Bohr effect. ${ }^{34}$

\section{Tobacco smoking}

Acute myocardial infarction or sudden death in patients with coronary artery disease is among the disorders strongly associated with cigarette smoking. ${ }^{35}$

Cigarette smoking is associated with increased levels of carboxyhemoglobin in the blood. This leads to a decrease in available hemoglobin for oxygen transport and will shift the ODC to the left, decreasing the volume of oxygen that can be unloaded to the tissue at any given $\mathrm{PO}_{2}$. Carbon monoxide also reduces the formation of 2, 3-DPG by inhibiting glycolysis in the erythrocytes. The $\mathrm{P}_{50}$ of the ODC was decreased $4 \mathrm{mmHg}$ in a study of cigarette smoking. ${ }^{36,37}$ Smoking also releases the sympathetic neurotransmitter norepinephrine and the adrenomedullary hormone epinephrine and may thereby increase tissue oxygen demand. ${ }^{38}$ The oxygen availability or demand ratio will, therefore, decrease and the oxygen deficit may participate in adverse changes in the cardiovascular system.

\section{Alcohol abuse}

The metabolic effects of alcohol in man are complex since some are due to the direct action of ethanol or its metabolites, whereas some are related to the changes in the redox state or to nutritional factors. ${ }^{39}$ Hypophosphatemia and phosphate depletion are well recognized consequences of acute and chronic alcohol abuse. ${ }^{40}$ Hypophosphatemia has been suggested to cause myopathy, rhabdomyolysis, and cardiomyopathy. ${ }^{41}$ Hypophosphatemia may be caused by a reduced renal threshold concentration of phosphate, but this might be only a part of a more complex tubular dysfunction. ${ }^{42,43}$ The presence of glycosuria and aminoaciduria with reduced renal threshold concentration of phosphate suggests a generalized reduction in the reabsorption ability of the proximal tubules. These data are supported by experimental studies indicating that ethanol interferes with the carrier function of the tubular cells by decreasing $\mathrm{Na}^{+} / \mathrm{K}^{+}$-ATPase activity.

Red cell 2, 3-DPG has been found to be increased, which has been suggested to be caused by a decrease in $\mathrm{CO}_{2}$ production (cellular oxidation of alcohol produces 33\% less $\mathrm{CO}_{2}$ than cellular oxidation of glucose) leading to increased red cell glycolysis compensatory to the left shift of the ODC due 
to the Bohr effect. ${ }^{44}$ The similarities of alcohol intoxication and oxygen deprivation warrant further studies.

\section{Hypertension}

Ljunghall and Hedstrand ${ }^{45}$ conducted a population study of more than 2,000 men aged 49-50 years and showed that plasma $\mathrm{Pi}$, within normal range, was inversely related to blood pressure. The presence of hypophosphatemia in hypertension has repeatedly been confirmed. ${ }^{46,47}$ Interestingly, a significant correlation was found between the rise in the initially low plasma Pi and the lowering of the initially high arterial blood pressure in overweight patients with essential hypertension. ${ }^{48}$

In spontaneous hypertensive rats, it was shown that the Pi and ATP in the vascular walls were reduced and that this reduced energy availability may contribute to a reduced response to vasoconstrictor agonists (noradrenaline and angiotensin II). ${ }^{49}$ Bindels et $\mathrm{al}^{50}$ in their study of hypertensive rats found that a disturbance in phosphate metabolism was already present at 6 weeks of age and that hypophosphatemia and hypophosphaturia were accompanied by an adaptive change in the transport capacity of $\mathrm{Na}^{+}$-dependent phosphate transport in brush border membranes from renal cortex. Older animals, at age 20 week, with marked hypophosphatemia showed reduced content of red cell 2, 3-DPG.

Epinephrine is a hypophosphatemic hormone in men, ${ }^{51}$ and patients with hypertension have often been found to have increased plasma catecholamine concentrations consistent with the theory of a pathophysiologic role for increased sympathetic activity in this disease..$^{52}$

\section{Metabolic syndrome}

There are different definitions of the metabolic syndrome. According to the Adult Treatment Panel III guidelines, metabolic syndrome is based on the presence of 3 or more of the following criteria: hypertension, impaired glucose tolerance, abdominal obesity, and dyslipidemia involving hypertriglyceridemia and decreased high-density lipoprotein cholesterol values. ${ }^{53}$

It was recently suggested that a disturbance in Pi metabolism may be a basic and fundamental representative of this metabolic syndrome. Håglin ${ }^{54}$ studied 2,752 consecutive patients (1,190 men, 1,562 women) admitted during the years 1986-1996 to the patient education centre of Vindeln, a small community in northern Sweden. It was found that a low plasma Pi was associated with high BMI, high blood glucose, high systolic and diastolic blood pressures, but low serum high-density lipoprotein and serum magnesium levels.
Another study by Kalaitzidis et al ${ }^{55}$ on 254 persons with a diagnosis of metabolic syndrome was based on Adult Treatment Panel III guidelines. Subjects with fewer than 3 criteria served as controls. Patients with metabolic syndrome showed significantly lower plasma Pi and magnesium levels than controls. Because the fractional excretion of phosphate was similar in both groups, it was assumed that hypophosphatemia in patients with metabolic syndrome was attributable to decreased dietary intake and internal redistribution of this element.

\section{Discussion}

Harden and Young ${ }^{56}$ in 1906 were the first to note that phosphorus played an important role in carbohydrate and energy metabolism, and the importance of phosphorus has been looming larger ever since. They furthermore found in living tissue a sugar-phosphate ester consisting of fructose with 2 phosphate groups, fructose diphosphate, also called Harden-Young ester. ${ }^{56} \mathrm{Pi}$ is an important substrate for ATP formation both by oxidative phosphorylation and by glycolysis. Because phosphate is a component of ATP, it also plays a pivotal role in the energy-related processes that take place in the endothelium and muscle cells of the cardiovascular system. ${ }^{57}$ Furthermore, without optimal oxygenation to the terminal electron acceptor in a reaction that is carried out by cytochrome c oxidase in the electron transport chain in mitochondria, the consequence of mitochondrial dysfunction may be endothelial dysfunction, increased endothelial permeability, or cell lyses.

Our study indicates that age, gender, hypertension, obesity, diabetes, hyperglyceridemia, and the metabolic syndrome all are associated with hypophosphatemia and increased risk for cardiovascular diseases. In addition, tobacco smoking, diabetes, and hyperchylomicronemia show defects in tissue oxygen delivery (Figure 1). In hypertension, microcirculation plays a critical role in that the increase in peripheral resistance underlying the raised blood pressure is localized to a narrowing of small arteries and precapillary arterioles with rarefaction of capillaries possibly leading to ischemic hypoxia. In diabetes, affinity hypoxia may be related to the increased levels of glycosylated hemoglobin, relative or absolute hypophosphatemia, and red cell 2, 3-DPG content. In diabetes mellitus, a major disturbance in phosphate handling occurs in the kidney tubules, where the excessive sodium-dependent glucose reabsorption in patients with diabetes depolarizes the electrochemical sodium gradient. Since Pi uses the same driving force but has less binding ability to sodium than glucose and aminoacids, such as 


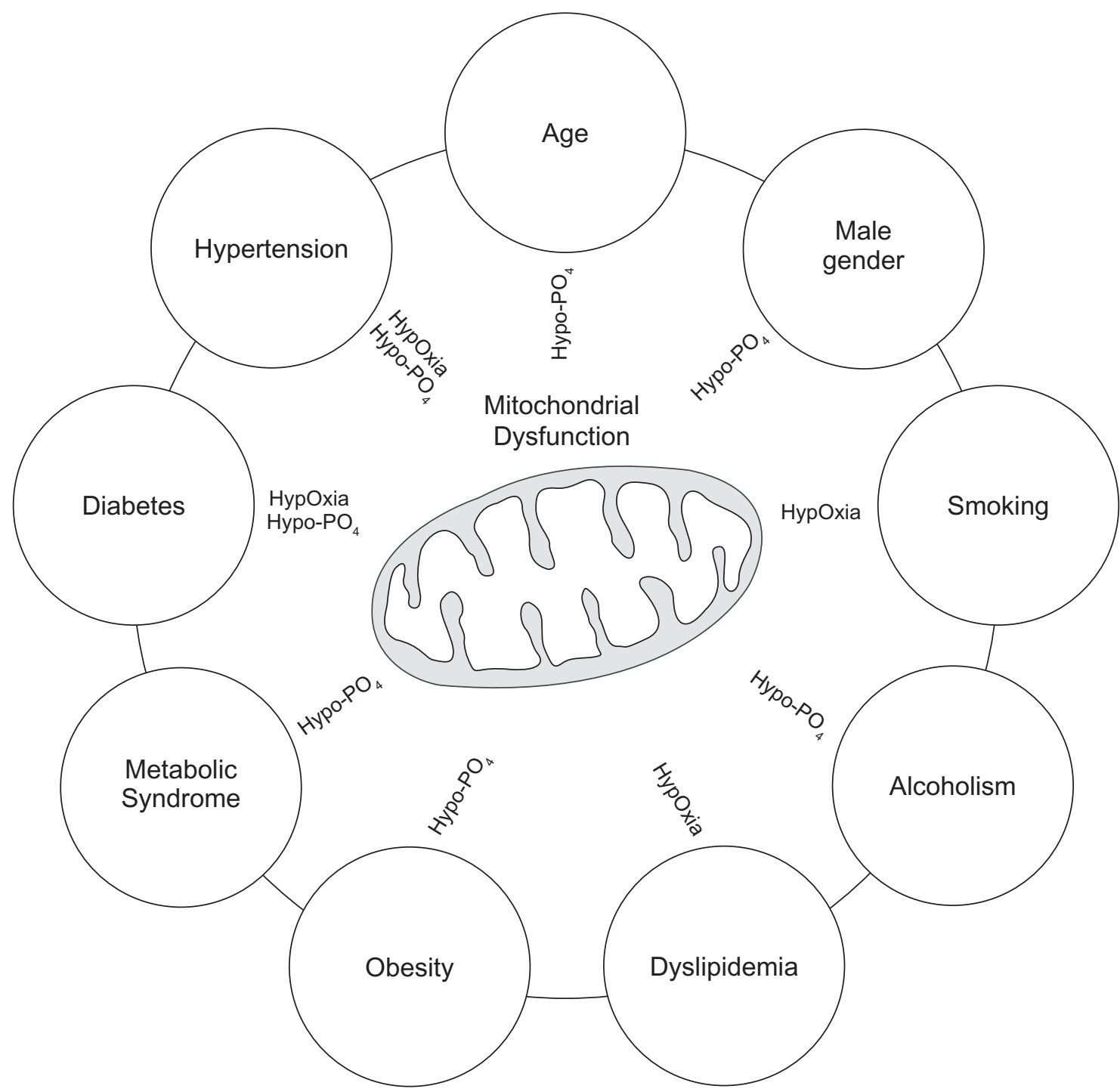

Figure I The present concept indicates that the risk factors to cardiovascular disease lead to mitochondrial dysfunction due to either hypophosphatemia and/or hypoxia (see text).

alanine, the Pi reabsorption, particularly in poorly regulated patients, become impaired. Sodium-dependent phosphate transport has been described in many epithelial cells and may be a widespread process. ${ }^{58}$ It occurs in cells in which the entrance of glucose is not controlled by insulin and the result of hyperglycemia is increased sodium-dependent glucose transport. Besides the renal tubular cells, this may occur in the cardiovascular endothelium. ${ }^{59}$

In a double-blind study over 1 year to assess the effect of addition of $2 \mathrm{~g}$ of calcium diphosphate to the 3 main meals to 43 patients with juvenile diabetes, no increase was seen in the concentration of $\mathrm{Pi}$ (active $=19,1.33 \mathrm{mmol} / \mathrm{L}$ vs placebo $=24,1.42 \mathrm{mmol} / \mathrm{L} ; P=\mathrm{ns})$. In the treatment group, the fasting urinary phosphate excretion significantly increased and the threshold concentration of $\mathrm{Pi}\left(T_{\mathrm{mPO} 4} / \mathrm{GFR}\right)$ was suppressed. The threshold concentration was not related to the level of PTH or to growth hormone, but inversely correlated with the degree of hyperglycemia. Therefore, the normalization of blood glucose levels leads to an improved capacity of the kidney tubules to reabsorb Pi and a subsequent increase in plasma Pi concentrations. ${ }^{6,60}$

The carbon monoxide, a byproduct of smoking, leads to a decrease in oxygen carrying capacity, a left shift (decreased $\mathrm{P}_{50}$ ) of the ODC, and a decrease in oxygen availability or demand ratio.

The large study by Park et $\mathrm{al}^{9}$ supports the findings of Håglin et $\mathrm{al}^{8}$ and that serum phosphate levels showed a negative correlation to age, BMI, fasting blood glucose, triglyceride levels, and systolic and diastolic blood pressures. However, it was also shown that it may be important to maintain an appropriate level of phosphate for the prevention of cardiovascular events and metabolic syndrome. 
It is well established that patients and animals with very low plasma concentration of Pi have abnormal function of red blood cells, kidneys, brain, myocardium, pancreas, muscles, and nerves. ${ }^{61,62}$ The relationship between extracellular and intracellular availability of $\mathrm{Pi}$ is uncertain because the availability of Pi in various intracellular compartments is not well known. Freeman et $\mathrm{a}^{63}$ used nuclear magnetic resonance to provide an estimate of free $\mathrm{Pi}$ in intact renal cortex of rats. From their data, they calculated the intracellular concentration of free Pi to be $0.6 \mathrm{mmol} / \mathrm{L}$. Brazy and Mandel ${ }^{64}$ used this estimate in combination with their own data relating phosphate dependence with oxidative phosphorylation in renal tubules and concluded that the availability of $\mathrm{Pi}$ in cortical renal tubules may be a factor in regulating rates of oxidative phosphorylation. They further showed that transepithelial phosphate transport provides Pi for use within cells and that intracellular metabolic processes compete for Pi. Perfusion of proximal convoluted tubules from rabbit kidney with phosphate-free medium containing glucose resulted in complete inhibition of the fluid absorption. It was suggested that as glycolysis increases, there is not enough intracellular phosphate for both glycolysis and mitochondrial respiration, and the rates of respiration decrease, thereby reducing the tissue content of ATP. Thus, these and other studies ${ }^{65,66}$ indicate that pathways of intracellular metabolism may depend on and compete for intracellular phosphate.

Plasma Pi concentration appears to act as a double-edged sword. Several epidemiological studies have indicated that calcium, phosphate, and calcium-phosphate product may also be positively associated with increased risk of cardiovascular diseases. ${ }^{67,68}$ Interestingly, vitamin D levels that are directly correlated with plasma Pi have been found to be inversely related with the risk of cardiovascular diseases. ${ }^{69}$ However, in end-stage renal failure, a U-shaped association of Pi and PTH to cardiovascular disease, with high risk in both hypophosphatemia and hyperphosphatemia, has been demonstrated. ${ }^{70,71}$ So, although we are dealing with complex processes, an explanation could be that hypophosphatemia leads to mitochondrial dysfunction and, in diabetes, to affinity hypoxia, whereas hyperphosphatemia promotes calcification of the vessel walls leading to ischemic hypoxia by narrowing or causing mechanical occlusion of both the macrovasculature and the microvasculature..$^{72-74}$

The negative effect of hypophosphatemia might be abrogated by increasing intracellular phosphate, which may be possible by using the key intermediate fructose 1,6-diphosphate (FDP). Natelson et $\mathrm{al}^{75}$ showed that orally administrated FDP as calcium salt was absorbed directly by the intestinal tract without splitting the phosphate linkage and that $6 \mathrm{~g}$ led to an increase of plasma Pi averaging 15\%, citric acid 10.7\%, and nonprotein organic phosphate, as much as, 173\%. Further preclinical and clinical data indicate that FDP can enter cells and serve as a metabolizable substrate of glycolysis. FDP acts as human bioenergy. It can transport phosphorous intracellularly and can deliver 4 mol of ATP per mole of FDP. FDP can be given orally and intravenously in humans and is well tolerated at pharmacological doses. Although FDP appears to be efficacious, no controlled study has been reported with this key intermediate in patients with cardiovascular risk factors.

\section{Disclosure}

The authors report no conflicts of interest in this work.

\section{References}

1. Bose S, French S, Evans SJ, Joubert F, Balaban RS. Metabolic network control of oxidative phosphorylation; multiple roles of inorganic phosphate. J Biol Chem. 2003;278:39155-39165.

2. Chance B, Leigh JS Jr, Kent J, et al. Multiple controls of oxidative metabolism in living tissues as studied by phosphorus magnetic resonance. Proc Natl Acad Sci U S A. 1986;83(24):9458-9465.

3. Hernando N, Gisler SM, Pribanic S, et al. NaPi-IIa and interacting partners. J Physiol. 2005;567:21-26.

4. Takeda E, Taketani Y, Sawada N, Sato T, Yamamoto H. The regulation and function of phosphate in the human body. Biofactors. 2004;21:345-355.

5. Bergwitz C, Jüppner H. Regulation of phosphate homeostasis by PTH, vitamin D, and FGF23. Annu Rev Med. 2010;61:91-104.

6. Ditzel J, Lervang H-H. Disturbance of inorganic phosphate metabolism in diabetes mellitus: temporary therapeutic intervention trials. Diabetes Metab Syndr Obes. 2009;2:173-177.

7. Ditzel J, Lervang H-H. Disturbance of inorganic phosphate metabolism in diabetes mellitus: its impact on the development of diabetic late complications. Curr Diabetes Rev. 2010;6(5):323-333.

8. Håglin L, Lindblad A, Bygren LO. Hypophosphataemia in the metabolic syndrome. Gender differences in body weight and blood glucose. Eur J Clin Nutr. 2001;55(6):493-498.

9. Park W, Kim BS, Lee JE, et al. Serum phosphate levels and the risk of cardiovascular disease and metabolic syndrome: a double-edged sword. Diabetes Res Clin Pract. 2009;83(1):119-125.

10. Isomaa B, Almgren P, Tuomi T, et al. Cardiovascular morbidity and mortality associated with metabolic syndrome. Diabetes Care. 2001; 24(4);683-689.

11. Lakka HM, Laaksonen DE, Lakka TA, et al. The metabolic syndrome and total and cardiovascular disease mortality in middle-aged men. JAMA. 2002;288(21):2709-2716.

12. American Heart Association. Heart disease and stroke stastitics-2010 update. Dallas, TX: American Heart Association; 2010.

13. Cirillo H, Ciacci C, de Santo NG. Age, renal tubular phosphate reabsorption, and serum phosphate levels in adults. $N$ Engl J Med. 2008;359(8):864-866.

14. Lindgärde F, Trell E. Serum inorganic phosphate and serum calcium in middle-aged men. II Relation to glucose and insulin parameters in glucose tolerance tests. Acta Med Scand. 1978;203(4):315-320.

15. DeFronzo RA, Lang R. Hypophosphatemia and glucose intolerance: evidence to tissue insensitivity to insulin. NEngl J Med. 1980;303(22): 1259-1263.

16. Nowicki M, Fliser D, Fode P, Ritz E. Changes in plasma phosphate levels influence insulin sensitivity under euglycemic conditions. J Clin Endocrinol Metab. 1996:81(1):156-159. 
17. Haap M, Heller E, Thamer C, Tschritter O, Stefan N, Fritsche A. Association of serum phosphate levels with glucose tolerance, insulin sensitivity and insulin secretion in non-diabetic subjects. Eur J Clin Nutr. 2006;60(6):734-739.

18. Torrance J, Jacobs P, Restrepo A, Eschbach J, Lenfant C, Finch CA. Intraerythrocytic adaption to anemia. N Engl J Med. 1970;283(4):165-169.

19. Sheldon GF, Sanders S, Fuchs R, Garcia J, Schooley J. Metabolism, oxygen transport and erythropoietin synthesis in anemia of thermal injury. Am J Surg. 1978;135(3):406-411.

20. Metcalfe J, Dhindsa DS, Edwards MJ, Mourdjinis A. Decreased affinity of blood for oxygen in patients with low output heart failure. Circ Res. 1969;25(1):47-51.

21. Woodson RD, Torrance JD, Shapell SD, Lenfant C. The effect of cardiac disease on hemoglobin oxygen binding. J Clin Invest. 1970;49(7):1349-1356.

22. Oski FA, Gottlib AJ, Delivoria-Papadopoulis M, Miller WW. Red cell 2, 3-diphosphoglycerate levels in subjects with chronic hypoxemia. N Engl J Med. 1969;280(21):1165-1166.

23. Valeri CR, Fortier NL. Red cell 2, 3-diphosphoglycerate and creatine levels in patients with red-cell mass deficits or with cardiopulmonary insufficiency. N Engl J Med. 1969;281(26):1452-1455.

24. Ditzel J, Standl E. Plasma Pi and erythrocyte 2, 3-DPG concentrations in non-acidotic diabetics in various degree of metabolic control. Clin Chem. 1976;22(4):550-551.

25. Ditzel J, Jaeger P, Standl E. An adverse effect of insulin on the oxygenrelease capacity of red blood cells in nonacidotic diabetics. Metabolism. 1978;27(8):927-934.

26. Ditzel J, Brøchner-Mortensen J, Kawahara R. Dysfunction of tubular phosphate reabsorption related to glomerular filtration and blood glucose control in diabetic children. Diabetologia. 1982;23(5):406-410.

27. Ditzel J, Andersen H, Daugaard-Peters N. Oxygen affinity of haemoglobin and red cell 2, 3 diphosphoglycerate in childhood diabetes. Acta Paediatr Scand. 1975;64:355-361.

28. Bunn HF, Briehl RW. The interaction of 2, 3-diphosphoglycerate with various hemoglobins. J Clin Invest. 1970;49:1088-1095.

29. Lindgärde F, Trell E. Serum inorganic phosphate in middle-aged men. I Inverse relation to body weight. Acta Med Scand. 1977;202(4): 307-311.

30. Lind L, Lithell H, Hvarfner A, Pollare T, Ljunghall S. On the relationship between mineral metabolism, obesity and fat distribution. Eur $J$ Clin Invest. 1993;23(5):307-310.

31. Ditzel J, Dyerberg J. The oxyhemoglobin dissociation curve in patients with familial hyperchylomicronemia. J Lab Clin Med. 1977;89(3): 573-580.

32. Ditzel J, Dyerberg J. Hyperlipoproteinemia, diabetes, and oxygen affinity of hemoglobin. Metabolism. 1977;26(2):141-150.

33. Poss MJ, Longmuir IS. The effect of hyperchylomicronemia on oxygen affinity in human blood. Adv Exp Med Biol. 1989;248:413-418.

34. Poss MJ, Longmuir IS, Moser ET. Hyperchylomicronemia, oxygen affinity and proton passage across red cell membrane. Adv Exp Med Biol. 1990;277:173-179.

35. Ambrose JA, Barua RS. The pathophysiology of cigarette smoking and cardiovascular disease. An update. J Am Coll Cardiol. 2004;43(10): 1731-1737.

36. Kambam JR, Chen LH, Hyman SA. Effect of short-term smoking halt on carboxyhemoglobin levels and $\mathrm{P}_{50}$ values. Anesth Analg. 1986;65(11): 1186-1188.

37. Rietbrock N, Kunkel S, Wörner W, Eyer P. Oxygen-dissociation kinetics in the blood of smokers and non-smokers: interaction between oxygen and carbon monoxide at the hemoglobin molecule. Naunyn Schmiedebergs Arch Pharmacol. 1992;345(1):123-128.

38. Cryer PE, Haymond MW, Santiago JV, Shah SD. Norepinephrine and epinephrine release and adrenergic mediation of smoking-associated hemodynamic and metabolic events. N Engl J Med. 1976;295(11): 573-577.

39. Mezey E. Metabolic effects of alcohol. Fed Proc. 1985;44(1): 134-138.
40. Knochel JP, Bilbrey GL, Fuller TJ, Carter NW. The muscle cell in chronic alcoholism: the possible role of phosphate depletion in alcoholic myopathy. Ann N Y Acad Sci. 1975;252(25):274-286.

41. Urbano-Marquez A, Estruch R, Navarro-Lopez F, Grau JM, Mont L, Rubin E. The effects of alcoholism on sketetal and cardiac muscle. N Engl J Med. 1989;320(7):409-415.

42. Angeli P, Gatta A, Caregardo L, et al. Hypophosphatemia and renal tubular dysfunction in alcoholism. Are they related to liver function impairment? Gastroenterology. 1992;100(2):502-512.

43. de Marchi S, Cecchin E, Basile A, Bertotti A, Nardini R, Bartoli E. Renal tubular dysfunction in chronic alcohol abuse-effects of abstinence. N Engl J Med. 1993;329(26):1927-1934.

44. Wood ME. Red blood cell 2, 3-diphosphoglyceric acid following ethanol consumption in man. Alcohol Alcohol. 1986;21(1):65-68.

45. Ljunghall S, Hedstrand $\mathrm{H}$. Serum phosphate inversely related to blood pressure. Br Med J. 1977;1(6060):553-554.

46. Kjeldsen SE, Os I, Westheim A, et al. Decreased serum phosphate in essential hypertension. Related to increased sympathetic tone. Am J Hypertens. 1988;1(4):403-409.

47. Uza G. Hypophosphatemia in patients with essential arterial hypertension. J Trace Elem Electrolytes Health Dis. 1990;4(4):245-248.

48. Uza G, Pavel O, Uza D, Vlaicu R. Effect of propranolol on hypophosphatemia in overweight. Int J Obes. 1982;6(5):507-511.

49. Saglikes Y, Massry SG, Iseki K, et al. Effect of phosphate depletion on blood pressure and vascular reactivity to norepinephrine and angiotensin II in the rat. Am J Physiol. 1985;248(1 Pt 2):F93-F99.

50. Bindels RJ, Geertsen JA, van Os CH. Increased transport of inorganic phosphate in renal brush borders of spontaneous hypertensive rats. Am J Physiol. 1986;250(3 Pt 2):F470-F475

51. Body JJ, Cryer PE, Offord KP, Heath H III. Epinephrine is a hypophosphatemic hormone in man. J Clin Invest. 1983;71(3):572-578.

52. Goldstein DS. Plasma catecholamines and essential hypertension. An analytical review. Hypertension. 1983;5(1):86-99.

53. Expert Panel on Detection, Evaluation, and Treatment of High Blood Cholesterol in Adults. Executive summary of the third report of the National Cholesterol Education Program(NCEP) expert panel on detection, evaluation, and treatment of high blood cholesterol in adults (Adult Treatment Panel III). JAMA. 2001;285(19):2486-2497.

54. Håglin L. Hypophosphataemia: cause of the disturbed metabolism in the metabolic syndrome. Med Hypotheses. 2001;56(6):657-663.

55. Kalaitzidis R, Tsimihodimos V, Bairaktari E, Konstantinos C, Siamopoulos M, Elisaf M. Disturbances of phosphate metabolism: another feature of metabolic syndrome. Am J Kidney Dis. 2005;45(5): 851-858.

56. Harden A, Young WJ. The alcoholic ferment of yeast-juice. Proc Roy Soc (Ser. B). 1906;77:405-420.

57. Wu F, Zhang EY, Zhang J, Bache RJ, Beard D. Phosphate metabolite concentrations and ATP hydrolysis potential in normal and ischaemic hearts. J Physiol. 2008;586(17):4193-4208

58. Escoubet B, Djalbali K, Amiel C. Adaption to Pi deprivation of cell Na-dependent Pi uptake: a widespread process. Am J Physiol. 1989; 256(2 Pt 1):C322-C328.

59. Corkey RF, Corkey BE, Cimbrone MA Jr. Hexose transport in normal and SV40-transformed human endothelial cells in culture. J Cell Physiol. 1981;106(3):425-434.

60. Ditzel J, Lervang HH, Brøchner-Mortensen J, Rødbro P. The influence of a dietary supplement of calcium and phosphate on bone mineral content and mineral homeostasis of diabetic children. Diabetologia. 1993; (Supp1 1):A58.

61. Knochel JP. The pathophysiology and clinical characteristics of severe hypophosphatemia. Arch Intern Med. 1977;137(2):203-220.

62. Amanzadeh J, Reilly RF Jr. Hypophosphatemia: an evidence-based approach to its clinical consequences and management. Nat Clin Pract Nephrol. 2006;2:136-145.

63. Freeman D, Bartlett S, Radda G, Ross B. Energenics of sodium transport in kidney. Saturation transfer ${ }^{31} \mathrm{P}-\mathrm{NMR}$. Biochim Biophys Acta. $1983 ; 762(2): 325-336$ 
64. Brazy PC, Mandel LJ. Does availability of inorganic phosphate regulate cellular oxidative metabolism? News Physiol Sci. 1986;1:100-103.

65. Koobs DH. Phosphate mediation of the Crabtree and Pasteur effects. Science. 1972;178(57):127-133.

66. Sestoft L, Bartels PD. Regulation of metabolism by inorganic phosphate. In: Hue L, van de Werve G, editors. Short-term Regulation of Liver Metabolism. Amsterdam: North Holland; 1981:427-452.

67. Foley RN. Phosphate levels and cardiovascular disease in the general population. Clin J Am Soc Nephrol. 2009;4(6):1136-1139.

68. Foley R, Collins AJ, Ishani A, Kalra PA. Calcium-phosphate levels and cardiovascular disease in community-dwelling adults: the Atherosclerosis Risk in Communities (ARIC) Study. Am Heart J. 2008;156(3): 556-563.

69. Papandreaou D, Malindretrics P, Karabouta Z, Rousso I. Possible health implications and low vitamin D status during childhood and adolescence. An updated mini review. Int J Endocrinol. 2010;2010:472173.

70. Naves-Diaz M, Passlick-Deetjen J, Guinsburg JL, et al. Calcium, phosphorus, PTH and death rates in a large sample of dialysis patients from Latin America. The CORES Study. Nephrol Dial Transplant. 2010 May 31. [Epub ahead of print].
71. Floege J, Kim J, Ireland E, et al. Serum iPTH, calcium and phosphate, and the risk of mortality in a European haemodialysis population. Nephrol Dial Transplant. 2010 Apr 25. [Epub ahead of print].

72. Goodmann WG, Goldin J, Kuizon BD. Coronary-artery calcification in young adults with end-stage renal disease who are undergoing dialysis. N Engl J Med. 2000;342(20):1478-1483.

73. Raggi P, Boulay A, ChasanTaber S, et al. Cardiac calcification in adult hemodialysis patients. J Am Coll Cardiol. 2002;39(4):695-701.

74. Giachelli CM. Vascular calcification: in vitro evidence for the role of inorganic phosphate. J Am Soc Nephrol. 2003;14:S300-S304.

75. Natelson S, Klein M, Kramer B. The effect of oral administration of calcium fructose diphosphate on the serum organic phosphate, inorganic phosphate, calcium proteins, and citric acid levels. J Clin Invest. 1951;30(1):50-54.
Vascular Health and Risk Management

\section{Publish your work in this journal}

Vascular Health and Risk Management is an international, peerreviewed journal of therapeutics and risk management, focusing on concise rapid reporting of clinical studies on the processes involved in the maintenance of vascular health; the monitoring, prevention and treatment of vascular disease and its sequelae; and the involvement of

\section{Dovepress}

metabolic disorders, particularly diabetes. This journal is indexed on PubMed Central and MedLine. The manuscript management system is completely online and includes a very quick and fair peer-review system, which is all easy to use. Visit http://www.dovepress.com/ testimonials.php to read real quotes from published authors. 